\title{
Avaliação experimental do espectrômetro Alta II e sua aplicação na normatização brasileira
}

\author{
Experimental evaluation of Alta II spectrometer and its \\ application in the Brazilian standards
}

\begin{abstract}
Cláudia Donald Pereira
Deivis Luis Marinoski

Roberto Lamberts

Saulo Guiths

Enedir Ghisi

Resumo

Cláudia Donald Pereira Universidade Estadual de Londrina Londrina - PR - Brasil

Deivis Luis Marinoski Universidade Federal de Santa Catarina

Florianópolis - SC - Brasil

Roberto Lamberts Universidade Federal de Santa Catarina

Florianópolis - SC - Brasil

Saulo Güths Universidade Federal de Santa Catarina

Florianópolis - SC - Brasil

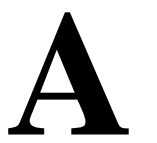

normatização brasileira relacionada ao desempenho termoenergético de edificações tem procurado inserir a refletância ou a absortância solar em seus critérios de análise. O objetivo deste artigo é analisar a exatidão e a repetibilidade de medições de refletância com o espectrômetro Alta II, bem como a influência da luminosidade do ambiente e da rugosidade da superfície sobre os valores medidos. Foram realizadas três séries de medições, variando os espectrômetros utilizados, a exposição à luz, e a rugosidade da superfície avaliada. Medições com o espectrofotômetro Lambda 1050 serviram de referência. A análise demonstrou que os resultados podem apresentar imprecisão elevada, com incerteza de $\pm 0,10$ nos valores absolutos de refletância solar. Sendo assim, o usuário do espectrômetro Alta II deve utilizá-lo com precaução, considerando tal erro. Também foi possível observar neste estudo que o Alta II pode ser usado especialmente para análise de superfícies planas e lisas. Além disso, deve-se garantir que as medições sejam realizadas com o cuidado de evitar a infiltração de luz através da superfície de contato entre o equipamento e a amostra.

Palavras-chave: Medição. Refletância solar. Absortância solar. Normas. Alta II. Eficiência energética. Edificações.

\section{Abstract \\ Solar reflectance and solar absorptance are directly responsible for the behaviour the thermal and energy performance of buildings has sought to include such properties in its analysis criteria. The objective of this paper is to analyse the accuracy and repeatability of reflectance measurements using the Alta II spectrometer, as well as the influence of ambient light and surface roughness on the measured values. Three series of measurements were performed by varying: the spectrometers used, the exposure to light, and the roughness of the measured surface (flat painted samples or texture painted walls). Measurements were also performed using the Lambda 1050 spectrophotometer as a reference. The analysis showed that the results may be highly inaccurate. Therefore, the Alta II spectrometer should be used with caution. The experiments showed uncertainty of about \pm 0.10 in the absolute values of solar reflectance (for reflectance ranging from 0-1). Thus, the Alta II spectrometer user must consider such an error. It was also concluded that Alta II should only be used to analyse flat surfaces and it is important to ensure that measurements are carried out preventing light leakage through contact between the equipment surface and the sample.} of surfaces concerning incident solar radiation. The Brazilian regulation related to

Enedir Ghisi Universidade Federal de Santa Catarina Florianópolis - SC - Brasil

Recebido em 13/06/16 Aceito em 28/06/16

Keywords: Measurement. Solar reflectance. Solar absorptance. Standards. Alta II. Energy efficiency. Buildings.
\end{abstract}

PEREIRA, C. D.; MARINOSKI, D. L.; LAMBERTS, R.; GÜTHS, S.; GHISI, E. Avaliação experimental do espectrômetro 


\section{Introdução}

Parte considerável da energia elétrica fornecida em todo o mundo é consumida no condicionamento artificial de edificações. Esse consumo pode ser minimizado a partir da adoção de estratégias para melhoria do desempenho térmico e eficiência energética das edificações. A envoltória da edificação é protagonista nas trocas de calor com o ambiente externo. A refletância e a absortância solar têm grande impacto no desempenho térmico da envoltória, pois determinam os ganhos de calor devido à incidência da radiação solar. Quando a energia radiante atinge uma superfície opaca, uma parte dessa energia é refletida e outra absorvida. A soma dessas duas parcelas é igual à energia total incidente, portanto basta conhecer apenas uma das parcelas para também determinar a outra.

Sendo um país de clima predominantemente tropical, o Brasil recebe intensa insolação ao longo de todo o ano. Isso faz com que as propriedades térmicas dos revestimentos externos sejam uma preocupação no que diz respeito a mitigar o impacto da incidência da radiação solar na carga térmica dos edifícios. Os regulamentos brasileiros de eficiência energética e a norma de desempenho de edificações (INSTITUTO..., 2010, 2012; ABNT, 2013) inseriram a absortância solar em seus critérios de análise. A adoção de revestimentos, não apenas por questões estéticas, mas também de desempenho, ainda é vista com descaso por alguns projetistas. Dessa forma, os critérios estabelecidos em normas e regulamentos são de extrema relevância para favorecer o desempenho termoenergético das edificações. Mas, para que os regulamentos possam ser aplicados na prática, é necessário conhecer a absortância ou a refletância solar de tais revestimentos.

A radiação solar se propaga na forma de ondas eletromagnéticas. O Sol emite radiação com mais intensidade nos comprimentos de onda de $0,3 \mu \mathrm{m}$ a 2,5 $\mu \mathrm{m}$ aproximadamente. Parte dessa radiação é emitida como luz visível que é capaz de sensibilizar o olho humano. O restante da radiação solar é emitido como radiação ultravioleta e infravermelha (de onda curta), que não são percebidas pelo olho humano (INCROPERA et al., 2011).

A American Society for Testing and Materials (ASTM) apresenta três métodos para medição de refletância solar de superfícies.

A E903 (AMERICAN..., 2012a) indica o uso de espectrofotômetro com esfera integradora para medição de refletância espectral em laboratório. Esse método é o mais adequado e preciso para medições em pequenas superfícies planas e homogêneas. Os valores de refletância espectral obtidos com espectrofotômetro precisam ser ajustados a um espectro solar padrão para o cálculo da refletância solar.

A C1549 (AMERICAN..., 2009) propõe o uso de um refletômetro solar portátil padrão para medição da refletância solar. Ele é indicado para medições de superfícies planas opacas, homogêneas ou heterogêneas, com dimensões maiores que $3 \mathrm{~cm}$ x 3 $\mathrm{cm}$. O equipamento permite a realização de medições em laboratório ou em campo. A norma C1549 (AMERICAN..., 2009) cita que medidas realizadas com o refletômetro comparadas a resultados obtidos com espectrofotômetro, para os mesmos materiais, atingiram uma incerteza absoluta de até $3 \%$.

A E1918 (AMERICAN..., 2006) apresenta um método para avaliações em campo utilizando um piranômetro. Para a aplicação desse método, a superfície analisada precisa possuir pelo menos $4 \mathrm{~m}$ de diâmetro e baixa inclinação (menor que 9,5 $5^{\circ}$. Esse é o único dos métodos que pode ser adotado no caso de avaliação de superfícies com rugosidade elevada.

Esses três métodos para medição de refletância indicam o uso de equipamentos que costumam ter preço elevado e exigem especialidade para seu manuseio e operação. Como consequência, é comum a adoção de valores de absortância e refletância solar com base apenas nas cores dos materiais, seguindo tabelas como as apresentadas pela norma brasileira NBR 15220-2 (ABNT, 2005) ou em publicações de referências internacionais (AMERICAN..., 2005). Porém, essa solução gera erros e incertezas (CASTRO et al., 2003; DORNELLES; RORIZ, 2007), sendo necessário buscar melhores alternativas.

Algumas pesquisas têm sido realizadas no Brasil adotando como alternativa para avaliação da refletância solar o uso do espectrômetro Alta II (DORNELLES; RORIZ, 2007; DORNELLES, 2008; SANTOS; MARINOSKI; LAMBERTS, 2009; SANGOI; RAMOS; LAMBERTS, 2010; MARINOSKI et al. 2013, MUNIZ; PEZZUTO, 2014). Este equipamento apresenta como principais benefícios o fato de ser portátil (permite uso em campo) e o custo reduzido, muito inferior ao de um espectrofotômetro ou de um refletômetro padrão.

Assim, este artigo apresenta uma avaliação experimental do espectrômetro portátil Alta II. O objetivo é analisar a exatidão e a repetibilidade do equipamento, bem como a influência da luminosidade do ambiente e da rugosidade da superfície sobre os valores de refletância/absortância solar medidos. Com base 
nos resultados também são feitas recomendações sobre o uso do equipamento e sua aplicação na normatização brasileira.

\section{Materiais e método Espectrômetro Alta II}

O Alta II é um equipamento para medição de refletância espectral desenvolvido pelo Lunar and Planetary Institute, de Houston - Texas. Ele foi criado como uma ferramenta didática para ensino sobre cor, luz e espectroscopia em escolas de ensino médio dos Estados Unidos (LUNAR..., 2011).

Com o Alta II, pode-se realizar medições correspondentes a radiações em onze diferentes comprimentos de onda, entre $470 \mathrm{~nm}$ e $940 \mathrm{~nm}$, sendo sete deles na região visível e quatro na região do infravermelho próximo. Na parte superior do equipamento (Figura 1a) há um botão para ligar e desligar e onze botões de medição, um para cada comprimento de onda a ser analisado. Há também uma tela, onde é apresentado o valor do sinal de resposta em milivolts.

$\mathrm{Na}$ parte inferior do equipamento (Figura 1b) existe uma abertura com onze leds, dispostos em círculo. Cada lâmpada emite a energia correspondente a um comprimento de onda e é acionada por um dos botões. Ao pressionar um botão, acende-se a lâmpada correspondente, que emite certa quantidade de energia. Um sensor, localizado no centro da abertura inferior, detecta a quantidade de energia que é refletida. Com os valores espectrais para os onze comprimentos de onda, calcula-se a refletância total para o intervalo (entre 470 nm e 940 $\mathrm{nm})$.

O espectrômetro Alta II é de fácil manuseio, porém alguns cuidados são indicados para minimizar imprecisões nos resultados. Para a realização de medições, o equipamento deve ser posicionado sobre a amostra, de forma que esta cubra totalmente a abertura inferior. A amostra deve ser plana e permitir o contato total entre sua superfície e a superfície posterior do espectrômetro.

O Alta II fornece, em sua tela, valores em milivolts $(\mathrm{mV})$, que devem ser convertidos em valores de refletância a partir de cálculos matemáticos. Para isso é necessário também utilizar uma amostra de referência ${ }^{1}$, com refletância espectral já conhecida para os onze comprimentos de onda do espectrômetro.

Para iniciar a medição, o Alta II é ligado e posicionado sobre a amostra de referência. $\mathrm{O}$ valor inicial que aparece na tela do equipamento é chamado voltagem de fundo, e é um dos dados necessários para o cálculo. Em seguida, cada botão referente aos comprimentos de onda deve ser acionado (um por vez), sendo anotados manualmente os valores de voltagem da amostra de referência para todos os comprimentos de onda.

Após a medição da amostra de referência, são realizadas as medições na amostra em avaliação. O Alta II é posicionado sobre a superfície da amostra, sendo então medida a voltagem de fundo. Depois, medem-se as voltagens da amostra para os onze comprimentos de onda.

\section{Figura 1 - Espectrômetro Alta II}

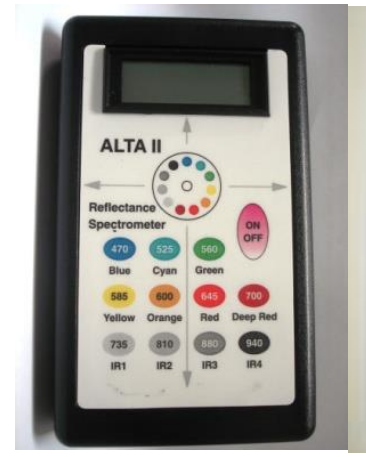

(a) vista superior

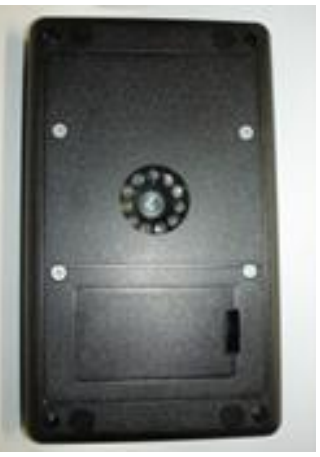

(b) vista inferior

Fonte: Marinoski et al. (2013).

\footnotetext{
${ }^{1} \mathrm{~A}$ amostra de referência pode ser composta de qualquer material com superfície plana e lisa, tendo esta exigência: ter os valores de refletâncias espectrais previamente conhecidos por meio de medição em espectrofotômetro, conforme o método da norma ASTM E903 (AMERICAN..., 2012a).
} 
A partir dos valores medidos, as refletâncias espectrais da amostra são calculadas para cada comprimento de onda por meio da Equação 1.

$\rho_{\lambda, \text { amostra }}=\left(\frac{V_{\lambda, \text { amostra }}-V_{f, \text { amostra }}}{V_{\lambda, \text { ref }}-V_{\text {f,ref }}}\right) \times \rho_{\lambda \text { ref }} \quad$ Eq. 1

Onde:

$\rho_{\lambda \text {,amostra }}$ é a refletância da amostra para um determinado comprimento de onda $\lambda(\%)$;

$\mathrm{V}_{\lambda, \text { amostra }}$ é a voltagem da amostra medida no comprimento de onda $\lambda(\mathrm{mV})$;

$\mathrm{V}_{\mathrm{f} \text {,amostra }}$ é a voltagem de fundo da amostra $(\mathrm{mV})$;

$\mathrm{V}_{\lambda \text {,ref }}$ é a voltagem da amostra de referência medida no comprimento de onda $\lambda(\mathrm{mV})$;

$\mathrm{V}_{\mathrm{f}, \mathrm{ref}}$ é a voltagem de fundo da amostra de referência $(\mathrm{mV})$; e

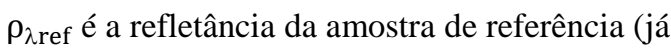
conhecida), no comprimento $\lambda(\%)$.

Com as medições no Alta II se obtém os valores de refletância espectral da amostra para cada um dos comprimentos de onda do equipamento, considerando a irradiância constante ao longo de todo o espectro avaliado. Entretanto, a intensidade da radiação solar que chega à superfície da Terra não é igual em todas as frequências. Sendo assim, para a obtenção da refletância solar da amostra, os valores de refletância espectral obtidos devem ser ajustados de acordo com a intensidade da radiação solar para cada comprimento de onda, e integrados no intervalo medido. Esse ajuste é feito com base em dados de irradiação solar global espectral, fornecida a partir de um espectro solar padrão como o apresentado na G173 (AMERICAN..., 2012b).

Para cada comprimento de onda, a refletância espectral deve ser multiplicada pela irradiação solar global espectral (do espectro solar padrão) e integrada para o intervalo de comprimento de onda desejado. A refletância solar ajustada ao espectro solar padrão é obtida calculando o quociente da soma das intensidades de irradiação refletida pela soma das intensidades de irradiação solar global. O cálculo deve ser realizado por meio da Equação 2 (baseada na E903 (AMERICAN..., 2012a)).

$\rho_{\text {solar }}=\left(\frac{\sum_{i=1}^{n} \rho_{\lambda i} \cdot E_{\lambda i} \cdot \Delta \lambda_{i}}{\sum_{i=1}^{n} E_{\lambda i} \cdot \Delta \lambda_{i}}\right) \cdot 100$

Eq. 2

Onde:

$\rho_{\text {solar }}$ é a refletância solar (\%);

$\rho \lambda_{\mathrm{i}}$ é a refletância espectral no comprimento de onda $\lambda_{\mathrm{i}}$ (adimensional);

$\lambda_{\mathrm{i}}$ é o comprimento de onda (nm); e

$E_{\lambda_{\mathrm{i}}}$ é a irradiação solar global espectral (W/m².nm).

Conforme já descrito, a soma das parcelas de radiação solar refletida e absorvida é igual ao total da radiação incidente. Sendo assim, a absortância solar pode ser calculada a partir da refletância solar, conforme mostra a Equação 3.

$\rho_{\text {solar }}=\left(\frac{\sum_{i=1}^{n} \rho_{\lambda i} \cdot E_{\lambda i} \cdot \Delta \lambda_{i}}{\sum_{i=1}^{n} E_{\lambda i} \cdot \Delta \lambda_{i}}\right) \cdot 100$

Onde:

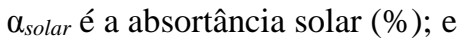

$\rho_{\text {solar }}$ é a refletância solar $(\%)$.

\section{Espectrofotômetro Lambda 1050}

Para servir de referência às medições com o equipamento Alta II, também foram realizadas medições com o espectrofotômetro modelo Lambda 1050, da marca PerkinElmer, mostrado na Figura 2.

O método de medição de refletância com espectrofotômetros, normatizado pela E903 (AMERICAN..., 2012a), é considerado um dos mais precisos. Tais equipamentos lançam feixes de luz sobre a amostra estudada nos mesmos comprimentos de onda abrangidos pelo espectro solar, e então a energia refletida é captada e medida. A partir dos valores de reflexão em cada comprimento de onda é possível calcular a refletância solar da amostra.

Figura 2 - Espectrofotômetro Lambda 1050 - PerkinElmer

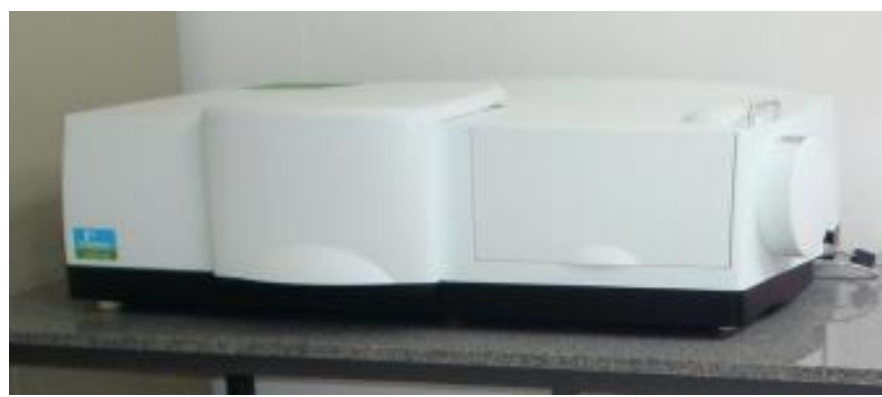

Fonte: Pereira (2014). 
A E903 (AMERICAN..., 2012a) indica que as medições devem ser realizadas na faixa de comprimento de onda de $300 \mathrm{~nm}$ a $2.500 \mathrm{~nm}$ aproximadamente. Nas medições com o espectrofotômetro também se obtém os valores de refletância espectral considerando uma irradiação constante ao longo de todo o espectro avaliado. Conforme já explicado, os valores de refletância espectral obtidos devem ser corrigidos de acordo com dados de irradiação solar global espectral. O cálculo deve ser realizado por meio da Equação 2 (baseada na E903 (AMERICAN..., 2012a)).

\section{Experimentos}

Foram realizadas três sequências de experimentos utilizando o espectrômetro Alta II, para avaliar:

(a) a exatidão e a repetibilidade de resultados obtidos com diferentes espectrômetros Alta II;

(b) a influência da luminosidade do ambiente sobre os resultados obtidos com o espectrômetro Alta II; e

(c) a influência da rugosidade da superfície sobre os resultados obtidos com o espectrômetro Alta II.

Os experimentos foram desenvolvidos considerando a realização de medições de refletância em algumas amostras pintadas com diferentes cores de acabamento e também a avaliação in loco de paredes de uma edificação real.
Para confecção das amostras, foram escolhidas tintas do tipo spray multiuso fosco nas cores branca, amarela, vermelha, azul e preta. Cada tinta foi aplicada, com três demãos, em chapas de alumínio de $10 \mathrm{~cm}$ x $10 \mathrm{~cm}$, com espessura de $1 \mathrm{~mm}$ (Figura 3Figura 4 - Superfícies da edificação analisadas em testes com o espectrômetro Alta II). Todas as tintas foram aplicadas utilizando spray (sem necessidade de diluição) a fim de obter pinturas homogêneas, com acabamento semelhante e com o mínimo de rugosidade.

No caso das superfícies da edificação, foram escolhidas paredes externas de um condomínio residencial, com revestimento texturizado em duas cores: salmão e bege (Figura 3).

Conforme já citado, para o cálculo da refletância das superfícies a partir das medições no Alta II, é necessária também a medição de uma amostra de referência, com refletância espectral já conhecida para os comprimentos de onda do equipamento. Como referência foi usada uma folha de papel branco formato A4 de $75 \mathrm{~g} / \mathrm{m}^{2}$, dobrada ao meio, que teve a refletância medida previamente no espectrofotômetro modelo Lambda 1050

Os resultados de cada medição, fornecidos pelo Alta II em milivolts, foram convertidos em valores de refletância, em porcentagem, realizando-se a Equação 1.

Figura 3 - Amostras utilizadas para testes com o espectrômetro Alta II

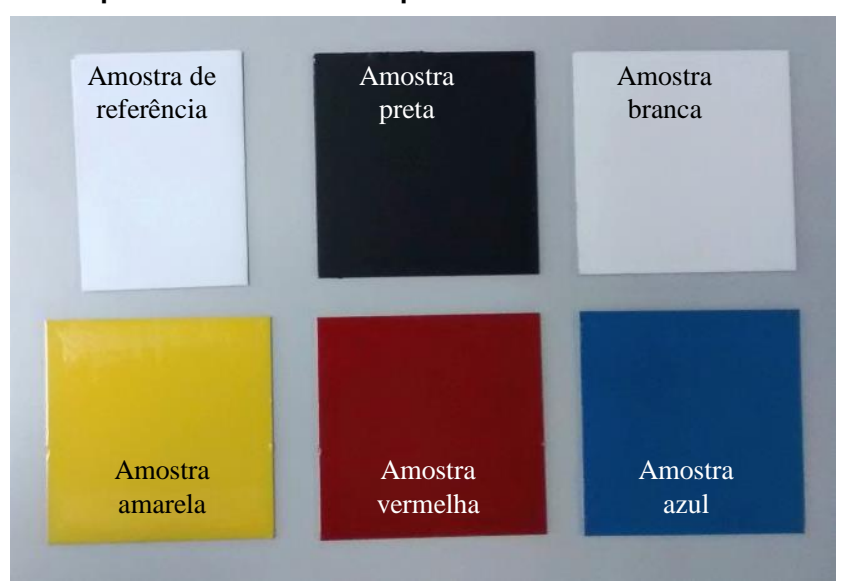

Figura 4 - Superfícies da edificação analisadas em testes com o espectrômetro Alta II

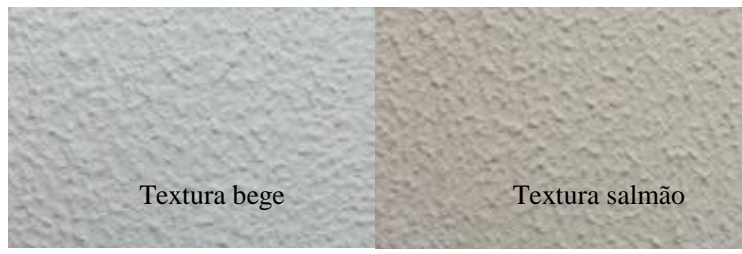




\section{Repetibilidade e exatidão dos resultados obtidos com o Alta II}

Alguns testes foram realizados a fim de verificar a exatidão e a repetibilidade dos resultados do Alta II. Para isso, foram testados cinco equipamentos (ID: 25010, 25011, 25013, 25016, 25019). Com estes cinco equipamentos, foram realizadas medições das cinco amostras de diferentes cores (Figura 3Figura 4 - Superfícies da edificação analisadas em testes com o espectrômetro Alta II). Cada amostra foi medida cinco vezes com cada equipamento, totalizando 125 medições.

A fim de verificar a repetibilidade dos dados obtidos com os espectrômetros Alta II, calculou-se o desvio padrão das cinco medições de cada amostra. Quanto menor o desvio padrão, maior é a capacidade do equipamento de apresentar o mesmo resultado para uma medição feita repetidas vezes.

Posteriormente, com os valores medidos, foram calculadas as refletâncias espectrais, ou seja, as refletâncias em cada comprimento de onda do equipamento, por meio da Equação 1. A partir desses valores, foram calculadas as médias das cinco medições, obtendo-se as refletâncias espectrais médias para cada amostra, nos onze comprimentos de onda do espectrômetro.

Por fim, com os valores de refletâncias espectrais médias, calculou-se um único valor de refletância solar para cada amostra em cada equipamento. Tais valores foram comparados à refletância solar obtida, para cada amostra, com o espectrofotômetro. Com isso foi possível indicar a exatidão dos equipamentos Alta II, ou seja, a conformidade de suas medições com relação aos valores de referência.

\section{Influência da luminosidade do ambiente nos resultados obtidos com o Alta II}

Por ser portátil, o equipamento Alta II tem sido muito utilizado para avaliações em campo, ou seja, medições em paredes e outras superfícies externas de edificações já construídas. Nas medições em campo, diferente do que ocorre em laboratório, não há controle das condições do ambiente, que podem interferir nas medições.

No caso das medições de refletância com o Alta II, é indicado que não haja infiltração de luz entre o equipamento e a superfície avaliada. Nas medições realizadas em superfícies que estão expostas à luminosidade excessiva, como quando há incidência de radiação solar direta, é possível que ocorra a infiltração de luz indesejada, o que compromete a confiabilidade dos resultados.

Para testar essa influência da luminosidade, foram realizadas medições das cinco amostras de diferentes cores (Figura 3) em três condições:

(a) durante o dia, expostas ao sol sem nenhuma proteção;

(b) durante o dia, expostas ao sol, mas com proteção para barrar a infiltração de luz; e

(c) durante a noite, com pouca luminosidade.

A proteção utilizada para barrar a infiltração de luz foi um tecido preto, grosso e opaco, colocado em volta do equipamento, conforme mostrado na Figura 5. Nesses testes foi utilizado apenas um espectrômetro Alta II (ID 25013), e cada amostra foi medida cinco vezes em cada uma das três condições, totalizando 75 medições.

Figura 5 - Proteção (tecido escuro) utilizada em medições com o Alta II

Com os resultados obtidos, calculou-se a média das cinco medições de cada amostra, em cada comprimento de onda, obtendo-se as refletâncias espectrais médias para cada amostra em cada condição. Tais valores foram comparados às refletâncias de referência, obtidas com o espectrofotômetro em condições controladas de laboratório, e verificaram-se as diferenças entre elas.

\section{Influência da rugosidade da superfície nos resultados obtidos com o Alta II}

Apesar de ser indicado essencialmente para medições em superfícies planas, em algumas situações o Alta II tem sido utilizado para realizar medições em superfícies rugosas, como pinturas texturizadas e pedras rústicas, utilizadas em revestimentos externos. Por isso, foram realizados testes de medição em duas superfícies rugosas. Eles foram realizados nessas superfícies com pinturas texturizadas (Figura 4) em três condições:

(a) durante o dia, expostas ao sol sem nenhuma proteção;

(b) durante o dia, expostas ao sol, mas com proteção para barrar a infiltração de luz; e

(c) durante a noite, com pouca luminosidade.

Nesses testes foi utilizado apenas um espectrômetro Alta II (ID 25013), e cada superfície foi medida cinco vezes em cada uma das três condições, totalizando 30 medições. Em todas as medições o espectrômetro foi posicionado no mesmo local (mesmo ponto em cada superfície). A proteção para barrar a infiltração de luz foi o mesmo tecido preto utilizado no experimento anterior (Figura 5).

A partir das medições nas duas superfícies, calcularam-se as refletâncias espectrais médias nos onze comprimentos de onda, em cada condição de exposição. Esses valores foram comparados entre si. Por tratar-se de paredes de uma edificação já construída, não foi possível analisar tais superfícies em laboratório através do espectrofotômetro.

\section{Uso do Alta II na normatização brasileira}

Atualmente a absortância solar é utilizada como parâmetro nos dois regulamentos brasileiros de eficiência energética em edificações e na norma brasileira de desempenho de edificações. Os regulamentos são os Requisitos Técnicos da Qualidade para o Nível de Eficiência Energética de Edifícios Comerciais, de Serviços e Públicos (RTQC) (INSTITUTO..., 2010), e o Regulamento Técnico da Qualidade para o Nível de Eficiência
Energética de Edificações Residenciais (RTQ-R) (INSTITUTO..., 2012). A norma de desempenho é a NBR 15575 (ABNT, 2013), que cita como referência para medição de refletância/absortância as normas E903 (AMERICAN..., 2012a), E1918 (AMERICAN..., 2006) e Standard 74 (AMERICAN..., 1988).

Considerou-se importante analisar a aplicabilidade do espectrômetro Alta II nas verificações relacionadas à referida normatização brasileira. Conforme descrito inicialmente, foram realizadas análises experimentais, que permitiram conhecer as incertezas dos resultados obtidos nas medições com espectrômetros Alta II. A partir de tais incertezas, e conhecendo os parâmetros das normas, foram indicadas restrições para o uso dos valores de absortância solar calculados a partir de medições com o Alta II.

\section{Resultados}

Os testes descritos foram realizados a fim de verificar a exatidão e a repetibilidade dos espectrômetros Alta II, além de verificar a influência da luminosidade do ambiente e da rugosidade das superfícies sobre os resultados das medições. Os resultados são apontados e analisados a seguir.

\section{Análise da repetibilidade}

Foram realizadas cinco medições em cada amostra, utilizando cinco diferentes espectrômetros Alta II. A partir dos valores obtidos nas leituras em milivolts $(\mathrm{mV})$, calculou-se o desvio padrão, que representa a variação do resultado de uma medição na mesma amostra realizada repetidas vezes. As médias dos valores em milivolts obtidas com cada equipamento (nos diferentes comprimentos de onda) são apresentadas na Tabela 1 .

Verificou-se que há maior desvio padrão, ou seja, menor repetibilidade, para as leituras em amostras com refletâncias mais elevadas. Todos os espectrômetros Alta II apresentaram maiores valores de desvio padrão nas leituras da amostra de cor branca e menores desvios na amostra de cor preta.

Não houve um canal (comprimento de onda) específico que claramente tenha apresentado menor repetibilidade que os outros. Avaliando as cores branca e preta (extremos), nota-se que para a cor branca o maior desvio foi de 7,54 $\mathrm{mV}$ (intervalo de 771-1034 mV, exceto voltagem de fundo), já na cor preta o maior desvio foi de $0,84 \mathrm{mV}$ (intervalo de 46-171 mV, exceto voltagem de fundo). 
Tabela 1 - Média das medições em milivolts das cinco leituras em cada comprimento de onda

\begin{tabular}{|c|c|c|c|c|c|c|c|c|c|c|c|c|c|}
\hline \multirow{2}{*}{ Amostra } & \multirow{2}{*}{$\begin{array}{c}\text { Equipamento } \\
\text { ID }\end{array}$} & \multicolumn{11}{|c|}{ Canal/Comprimento de onda (nm) } & \multirow[b]{2}{*}{ Fundo } \\
\hline & & 470 & 525 & 560 & 585 & 600 & 645 & 700 & 735 & 810 & 880 & 940 & \\
\hline \multirow{5}{*}{ Branca } & Alta 25010 & 882 & 1007 & 977 & 970 & 1000 & 932 & 868 & 837 & 960 & 899 & 850 & 131 \\
\hline & & 858 & 990 & 1034 & 938 & 1007 & 967 & 831 & 808 & 894 & 892 & 845 & 52 \\
\hline & Alta 25013 & 890 & 1016 & 1000 & 889 & 1001 & 914 & 863 & 904 & 889 & 858 & 870 & 82 \\
\hline & Alta 25016 & 913 & 984 & 1002 & 771 & 1001 & 958 & 914 & 850 & 883 & 897 & 857 & 21 \\
\hline & Alta 25019 & 851 & 993 & 985 & 989 & 935 & 938 & 868 & 870 & 957 & 886 & 860 & 18 \\
\hline \multirow{5}{*}{ Amarela } & 5010 & 183 & 606 & 644 & 685 & 750 & 714 & 651 & 624 & 695 & 662 & 635 & 130 \\
\hline & Alta 25011 & 108 & 566 & 661 & 667 & 751 & 738 & 613 & 613 & 653 & 661 & 634 & 52 \\
\hline & Alta 25013 & 141 & 612 & 679 & 646 & 771 & 715 & 667 & 686 & 644 & 652 & 663 & 82 \\
\hline & Alta 25016 & 65 & 550 & 626 & 530 & 737 & 724 & 666 & 631 & 612 & 654 & 634 & 19 \\
\hline & Alta 25019 & 77 & 581 & 640 & 691 & 683 & 725 & 648 & 639 & 681 & 649 & 653 & 18 \\
\hline \multirow{5}{*}{ Vermelha } & Alta 25010 & 149 & 152 & 174 & 250 & 374 & 502 & 477 & 488 & 527 & 505 & 495 & 131 \\
\hline & A & 81 & 84 & 122 & 208 & 352 & 515 & 442 & 480 & 480 & 505 & 501 & 52 \\
\hline & 5013 & 111 & 124 & 178 & 220 & 368 & 513 & 486 & 505 & 483 & 494 & 517 & 82 \\
\hline & 5016 & 34 & 39 & 66 & 140 & 303 & 474 & 454 & 463 & 442 & 466 & 467 & 20 \\
\hline & Alta 25019 & 48 & 50 & 100 & 193 & 265 & 498 & 460 & 456 & 493 & 484 & 502 & 18 \\
\hline \multirow{5}{*}{ Azul } & Alta 25010 & 430 & 294 & 224 & 188 & 178 & 202 & 217 & 480 & 477 & 508 & 488 & 131 \\
\hline & Alta 25011 & 392 & 247 & 184 & 126 & 117 & 155 & 151 & 460 & 422 & 503 & 485 & 52 \\
\hline & Alta 25013 & 430 & 291 & 207 & 155 & 149 & 193 & 192 & 136 & 437 & 510 & 522 & 82 \\
\hline & Alta 25016 & 387 & 206 & 133 & 69 & 72 & 109 & 120 & 456 & 386 & 470 & 462 & 19 \\
\hline & & 378 & 198 & 160 & 99 & 83 & 130 & 135 & 71 & 432 & 489 & 492 & 18 \\
\hline \multirow{5}{*}{ Preta } & & 159 & 163 & 168 & 165 & 164 & 157 & 159 & 164 & 171 & 165 & 166 & 131 \\
\hline & Alta 25011 & 96 & 100 & 116 & 101 & 110 & 112 & 90 & 98 & 97 & 108 & 106 & 52 \\
\hline & Alta 25013 & 134 & 141 & 144 & 126 & 129 & 148 & 121 & 127 & 136 & 134 & 146 & 82 \\
\hline & a 25016 & 51 & 55 & 53 & 46 & 53 & 51 & 48 & 56 & 61 & 63 & 70 & 21 \\
\hline & Alta 25019 & 62 & 68 & 84 & 79 & 74 & 79 & 62 & 67 & 70 & 75 & 75 & 18 \\
\hline
\end{tabular}

Tabela 2 - Média da refletância (\%) das cinco leituras em cada comprimento de onda

\begin{tabular}{|c|c|c|c|c|c|c|c|c|c|c|c|c|}
\hline \multirow{2}{*}{ Amostra } & \multirow{2}{*}{$\begin{array}{c}\text { Equipamento } \\
\text { ID } \\
\end{array}$} & \multicolumn{11}{|c|}{ Canal/Comprimento de onda (nm) } \\
\hline & & 470 & 525 & 560 & 585 & 600 & 645 & 700 & 735 & 810 & 880 & 940 \\
\hline \multirow{5}{*}{ Branca } & Alta 25010 & 90,7 & 91,9 & 88,9 & 87,5 & 86,3 & 88,6 & 88,8 & 84,4 & 85,9 & 85,1 & 84,5 \\
\hline & Alta 25011 & 90,8 & 90,3 & 86,9 & 83,4 & 83,5 & 84,8 & 85,3 & 79,2 & 83,9 & 80,8 & 81,0 \\
\hline & Alta 25013 & 87,2 & 87,1 & 85,9 & 82,5 & 81,8 & 83,6 & 83,7 & 84,9 & 83,4 & 78,6 & 78,5 \\
\hline & Alta 25016 & 88,7 & 90,9 & 89,7 & 89,1 & 86,7 & 87,2 & 86,8 & 84,0 & 87,3 & 84,7 & 83,6 \\
\hline & Alta 25019 & 86,9 & 87,2 & 83,7 & 82,2 & 82,2 & 83,3 & 82,6 & 84,0 & 83,0 & 78,3 & 78,1 \\
\hline \multirow{5}{*}{ Amarela } & Alta 25010 & 6,3 & 49,9 & 54,0 & 57,8 & 61,6 & 64,6 & 62,7 & 59,0 & 58,4 & 58,9 & 59,2 \\
\hline & Alta 25011 & 6,3 & 49,5 & 53,9 & 57,8 & 61,2 & 63,6 & 61,4 & 58,8 & 59,9 & 58,6 & 59,5 \\
\hline & Alta 25013 & 6,4 & 49,4 & 55,8 & 57,6 & 61,3 & 63,7 & 62,7 & 62,4 & 58,1 & 57,8 & 57,9 \\
\hline & Alta 25016 & 4,6 & 50,1 & 55,5 & 60,6 & 63,6 & 65,6 & 62,9 & 61,9 & 60,1 & 61,3 & 61,4 \\
\hline & Alta 25019 & 6,1 & 50,3 & 53,9 & 57,0 & 59,6 & 64,1 & 61,3 & 61,2 & 58,6 & 56,9 & 58,9 \\
\hline \multirow{5}{*}{ Vermelha } & Alta 25010 & 2,2 & 2,2 & 4,5 & 12,4 & 24,2 & 41,1 & 41,7 & 42,7 & 41,0 & 41,4 & 42,8 \\
\hline & Alta 25011 & 3,3 & 3,1 & 6,2 & 14,7 & 26,3 & 42,9 & 42,7 & 44,9 & 42,7 & 43,6 & 45,9 \\
\hline & Alta 25013 & 3,1 & 3,9 & 9,0 & 14,1 & 25,4 & 43,3 & 43,3 & 43,7 & 41,4 & 41,7 & 43,3 \\
\hline & Alta 25016 & 1,4 & 1,8 & 4,2 & 14,2 & 25,0 & 42,2 & 42,2 & 44,8 & 42,7 & 43,0 & 44,6 \\
\hline & Alta 25019 & 3,1 & 2,9 & 7,1 & 14,8 & 22,1 & 43,5 & 43,0 & 43,2 & 42,0 & 42,0 & 44,9 \\
\hline \multirow{5}{*}{ Azul } & Alta 25010 & 36,1 & 17,1 & 9,8 & 5,9 & 4,6 & 7,9 & 10,4 & 41,7 & 35,8 & 41,8 & 41,9 \\
\hline & Alta 25011 & 38,2 & 18,7 & 11,6 & 6,9 & 5,7 & 9,6 & 10,7 & 42,8 & 36,8 & 43,4 & 44,2 \\
\hline & Alta 25013 & 37,6 & 19,5 & 11,7 & 7,4 & 6,0 & 11,2 & 11,8 & 5,6 & 36,8 & 43,3 & 43,8 \\
\hline & Alta 25016 & 36,6 & 17,6 & 10,4 & 5,9 & 4,7 & 8,4 & 9,8 & 44,3 & 37,2 & 43,6 & 44,3 \\
\hline & Alta 25019 & 37,5 & 16,1 & 12,3 & 6,9 & 5,8 & 10,2 & 11,3 & 5,2 & 36,7 & 42,4 & 44,0 \\
\hline \multirow{5}{*}{ Preta } & Alta 25010 & 3,4 & 3,4 & 3,9 & 3,6 & 3,3 & 2,9 & 3,3 & 3,9 & 4,2 & 3,7 & 4,1 \\
\hline & Alta 25011 & 5,0 & 4,6 & 5,7 & 4,6 & 5,1 & 5,5 & 4,2 & 4,8 & 4,5 & 5,4 & 5,5 \\
\hline & Alta 25013 & 5,6 & 5,5 & 5,8 & 4,5 & 4,2 & 6,7 & 4,2 & 4,7 & 5,6 & 5,2 & 6,4 \\
\hline & Alta 25016 & 3,0 & 3,2 & 2,9 & 3,0 & 2,9 & 2,8 & 2,6 & 3,6 & 4,1 & 4,1 & 5,0 \\
\hline & Alta 25019 & 4,6 & 4,5 & 5,7 & 5,1 & 5,0 & 5,5 & 4,2 & 4,8 & 4,6 & 5,2 & 5,3 \\
\hline
\end{tabular}


Tabela 3 - Desvio padrão (considerando as refletâncias em \%) das cinco leituras em cada comprimento de onda

\begin{tabular}{|c|c|c|c|c|c|c|c|c|c|c|c|c|c|c|}
\hline \multirow{2}{*}{ Amostra } & \multirow{2}{*}{$\begin{array}{c}\text { Equipamento } \\
\text { ID }\end{array}$} & \multicolumn{11}{|c|}{ Canal/Comprimento de onda (nm) } & \multirow{2}{*}{\multicolumn{2}{|c|}{ Máximo }} \\
\hline & & 470 & 525 & 560 & 585 & 600 & 645 & $\mathbf{7 0 0}$ & 735 & 810 & 880 & 940 & & \\
\hline \multirow{5}{*}{ Branca } & Alta 25010 & 0,07 & 0,20 & 0,36 & 0,32 & 0,23 & 0,32 & 0,18 & 0,35 & 0,23 & 0,79 & 0,46 & 0,79 & \multirow{5}{*}{0,82} \\
\hline & a 25011 & 0,08 & 0,13 & 0,12 & 0,29 & 0,14 & 0,11 & 0,14 & 0,44 & 0,19 & 0,22 & 0,17 & 0,44 & \\
\hline & 25013 & 0,24 & 0,27 & 0,16 & 0,24 & 0,25 & 0,18 & 0,23 & 0,10 & 0,22 & 0,24 & 0,24 & 0,27 & \\
\hline & 5016 & 0,82 & 0,58 & 0,59 & 0,31 & 0,24 & 0,23 & 0,23 & 0,28 & 0,48 & 0,60 & 0,62 & 0,82 & \\
\hline & 0 & 0,13 & 0,20 & 0,35 & 0,11 & 0,08 & 0,12 & 0,10 & 0,17 & 0,22 & 0,19 & 0,23 & 0,35 & \\
\hline \multirow{5}{*}{ Amarela } & 0 & 0,13 & 0,09 & 0,11 & 0,09 & 0,08 & 0,09 & 0,10 & 0,11 & 0,09 & 0,06 & 0,05 & 0,13 & \multirow{5}{*}{0,28} \\
\hline & & 0,05 & 0,08 & 0,15 & 0,08 & & & 0,09 & & 0,08 & 0,13 & 0,11 & 0,15 & \\
\hline & $A$ & 0,05 & 0,08 & 0,18 & 0,17 & 0,13 & 0,10 & 0,05 & 0,28 & 0,09 & 0,14 & 0,09 & 0,28 & \\
\hline & 6 & 0,18 & 0,16 & 0,20 & 0,14 & 0,13 & 0,17 & 0,17 & 0,27 & 0,18 & 0,26 & 0,19 & 0,27 & \\
\hline & 9 & 0,06 & 0,08 & 0,20 & 0,21 & 0,14 & 0,16 & 0,09 & 0,18 & 0,22 & 0,18 & 0,18 & 0,22 & \\
\hline \multirow{5}{*}{ Vermelha } & & 0,07 & 0,00 & 0,05 & 0,05 & 0,04 & 0,10 & 0,05 & 0,08 & 0,07 & 0,10 & 0,43 & 0,43 & \multirow{5}{*}{0,59} \\
\hline & & 0,10 & 0,05 & 0,05 & 0,08 & 0,05 & 0,04 & 0,05 & 0,05 & 0,05 & 0,05 & 0,07 & 0,10 & \\
\hline & 25013 & 0,05 & 0,05 & 0,00 & 0,05 & 0,04 & 0,04 & 0,08 & 0,00 & 0,06 & 0,13 & 0,09 & 0,13 & \\
\hline & - & 0,09 & 0,10 & 0,08 & 0,15 & 0,13 & 0,14 & 0,15 & 0,15 & 0,20 & 0,23 & 0,59 & 0,59 & \\
\hline & & & 0,04 & 0,05 & 0,09 & 0,10 & 0,05 & 0,11 & 0,13 & 0,15 & 0,18 & 0,09 & 0,18 & \\
\hline \multirow{5}{*}{ Azul } & & & ד, ד, & 0,05 & 0,00 & & & 0,00 & 0,10 & 0,05 & 0,16 & 0,05 & 0,16 & \multirow{5}{*}{0,16} \\
\hline & & & & 0,05 & & & & 0,09 & & 0,08 & 0,14 & & 0,14 & \\
\hline & 25013 & 0,05 & 0,00 & 0,05 & 0,06 & 0,00 & 0,00 & 0,00 & 0,05 & 0,06 & 0,08 & 0,07 & 0,08 & \\
\hline & 25016 & 0,00 & 0,00 & 0,00 & 0,00 & 0,00 & 0,00 & 0,00 & 0,15 & 0,06 & 0,04 & 0,04 & 0,15 & \\
\hline & & 0,16 & 0,07 & 0,04 & 0,00 & 0,04 & 0,05 & 0,05 & 0,00 & 0,05 & 0,14 & 0,16 & 0,16 & \\
\hline \multirow{5}{*}{ Preta } & 25010 & 0,05 & 0,06 & 0,05 & 0,06 & 0,04 & 0,05 & 0,05 & 0,00 & 0,06 & 0,05 & 0,05 & 0,06 & \multirow{5}{*}{0,15} \\
\hline & 25011 & 0,00 & 0,04 & 0,00 & 0,05 & 0,04 & 0,05 & 0,06 & 0,05 & 0,04 & 0,07 & 0,00 & 0,07 & \\
\hline & 250 & 0,06 & 0,05 & 0,08 & 0,00 & 0,00 & 0,04 & 0,05 & 0,06 & 0,06 & 0,06 & 0,04 & 0,08 & \\
\hline & $A$ & 0,11 & 0,10 & 0,10 & 0,13 & 0,10 & 0,10 & 0,10 & 0,11 & 0,11 & 0,11 & 0,15 & 0,15 & \\
\hline & Alta 25019 & 0,09 & 0,04 & 0,07 & 0,05 & 0,05 & 0,05 & 0,05 & 0,05 & 0,05 & 0,05 & 0,07 & 0,09 & \\
\hline
\end{tabular}

Com os valores medidos no Alta II, em milivolts, foram calculadas as refletâncias espectrais médias de cada amostra, para cada um dos comprimentos de onda do equipamento. A Tabela 2 mostra os valores médios de refletância em cada comprimento de onda e a Tabela 3 apresenta o desvio padrão para o respectivo resultado. O resultado do máximo desvio encontrado na Tabela 3 expressa mais claramente como a variação em milivolts dada pela repetição das leituras tem baixa influência sobre os resultados finais da refletância. Nota-se que o maior desvio ocorre na tinta branca e não passa de $0,82 \%$ (absoluto, em uma escala de 0-100\%).

\section{Análise da exatidão}

Os valores de refletâncias espectrais médias obtidas, para cada amostra, a partir das medições com o Alta II, foram comparados a valores de referência, obtidos com espectrofotômetro nas mesmas amostras. Na Figura 6 podem ser observadas as curvas espectrais das cinco amostras avaliadas pelo Alta II e os valores de referência.

Em geral, as curvas espectrais dos espectrômetros Alta II alcançaram uma boa aproximação com a curva do espectrofotômetro, considerando os onze comprimentos de onda. Apenas no caso da amostra azul houve uma divergência relevante: no comprimento de onda de $735 \mathrm{~nm}$, em três dos equipamentos, os valores foram bem superiores aos de referência.

Posteriormente foi obtido o valor da refletância solar total para cada amostra medida em cada equipamento (Figura 6). Tais dados foram comparados à refletância solar obtida no espectrofotômetro para cada amostra. Com isso foi possível indicar a exatidão dos espectrômetros Alta II, ou seja, a conformidade de seus resultados com relação a valores de referência.

Os resultados obtidos por meio do uso dos espectrômetros Alta II indicam uma boa aproximação com os valores de referência obtidos com o espectrofotômetro para os mesmos comprimentos de onda (470 nm a $940 \mathrm{~nm}$ ). Nesta faixa, as diferenças entre a refletância determinada pelos espectrômetros Alta II e pelo espectrofotômetro foram de no máximo 2,80\% (absoluto).

Entretanto, a refletância solar deve considerar uma faixa mais ampla (UV, visível e infravermelho próximo). Quando se compara os resultados dos espectrômetros Alta II e a refletância solar total do espectrofotômetro, de $300 \mathrm{~nm}$ a $2.500 \mathrm{~nm}$, as diferenças chegam a 10,12\% (absoluto). Tal diferença é resultado principalmente da variação da refletância nos comprimentos de onda do infravermelho. 
A partir da incerteza máxima encontrada na análise de repetibilidade $(0,82 \%)$ e na comparação com o valor de referência do espectrofotômetro $(10,12 \%)$, o erro máximo considerado pode ser dado pela soma quadrática das incertezas, o que resulta em $\pm 10,15 \%$ (absoluto).

Figura 6 - Refletâncias espectrais das cinco amostras, na faixa de 470 nm a 940 nm, medidas no espectrofotômetro e nos cinco espectrômetros Alta II
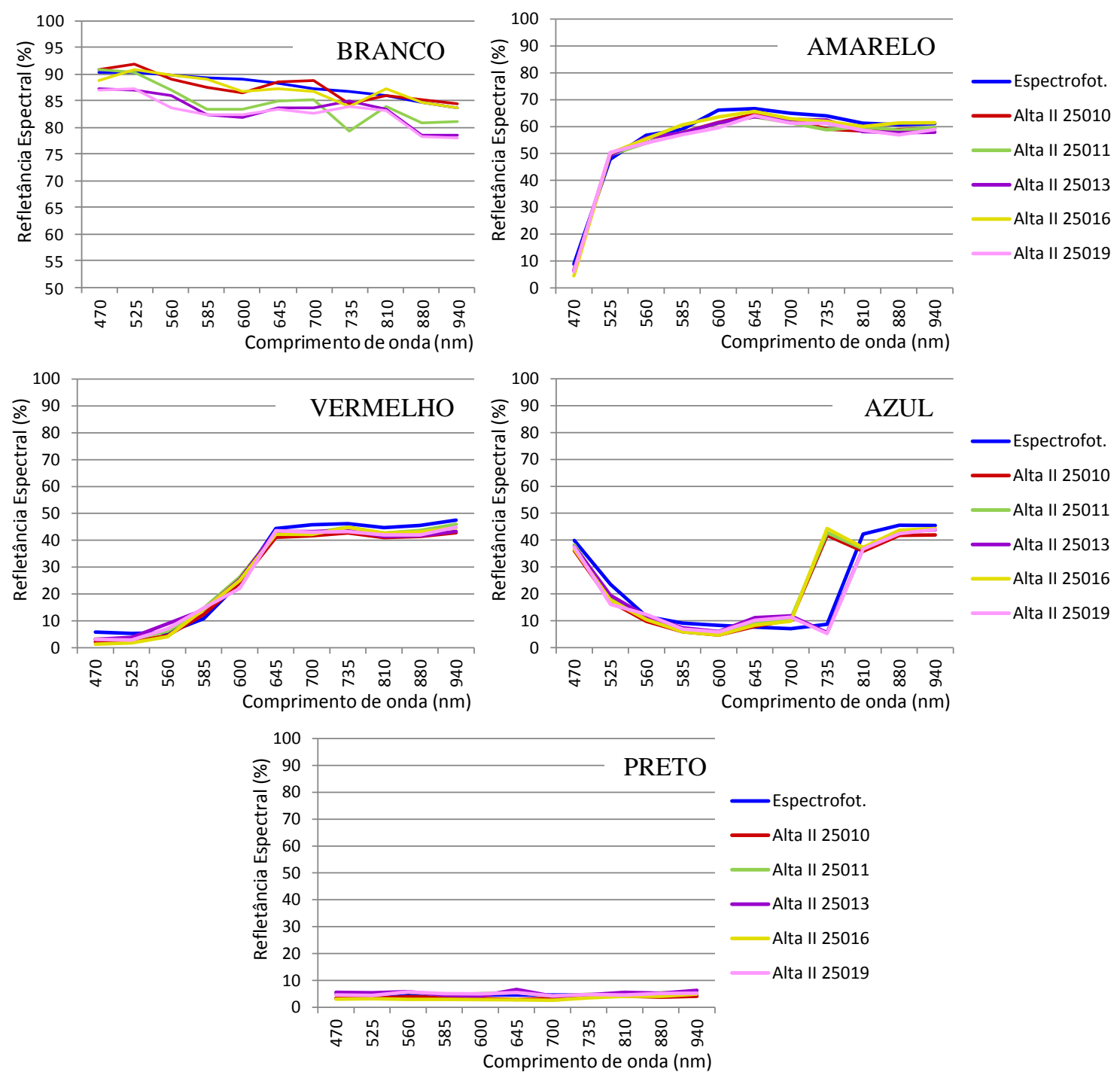

Figura 7 - Comparação dos resultados de refletância solar, calculados a partir das medições no espectrofotômetro e nos cinco espectrômetros Alta II

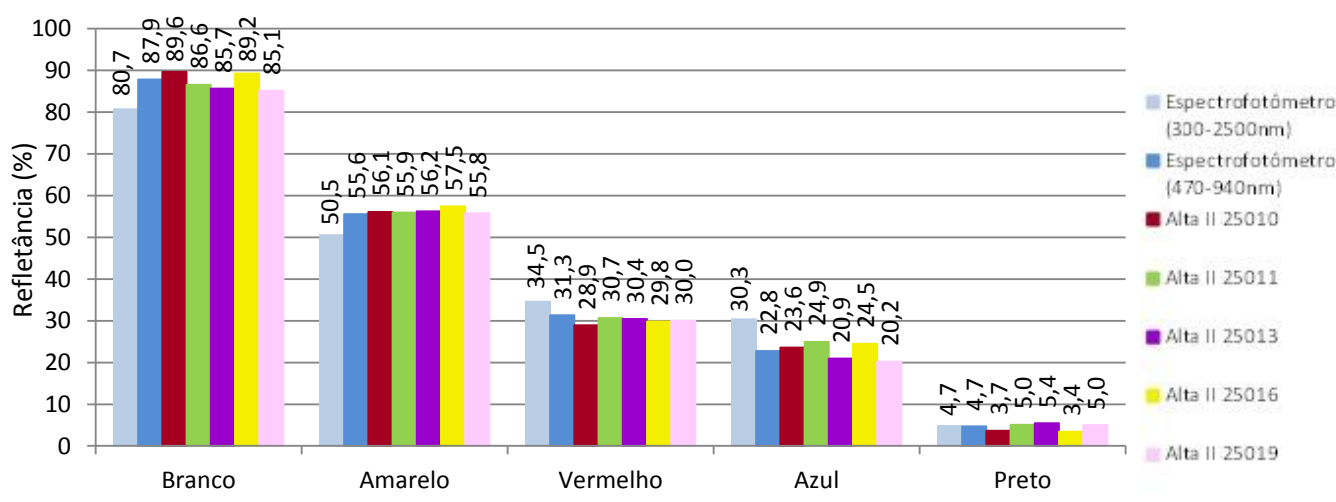


A Figura 8 mostra comparações de refletâncias espectrais medidas nos espectrômetros Alta II com as medições no espectrofotômetro em todo o espectro solar. Nota-se que as superfícies podem refletir a radiação solar de forma diferenciada na parcela infravermelha do espectro. Por exemplo, a superfície com a pintura branca apresentou elevada refletância na parcela visível, mas um declínio de tal valor ao longo do infravermelho. Na amostra preta, os valores de refletância são quase constantes ao longo do espectro solar. No caso da pintura amarela, vermelha e azul, a refletância tem oscilações (para mais ou para menos) em alguns comprimentos do infravermelho.
Observa-se que a variação da refletância espectral na faixa do infravermelho influencia diretamente o valor da refletância solar das amostras. Sendo assim, a análise indica que valores obtidos a partir de medições com o espectrômetro Alta II não deveriam ser considerados como "refletância solar", pois ele não cobre grande parte do espectro solar. Logo, os valores determinados com o espectrômetro Alta II podem ser considerados apenas como um indicativo da real refletância solar da superfície, como apontam outros estudos realizados anteriormente.

Figura 8 - Refletâncias espectrais das cinco amostras (Alta II x Espectrofotômetro)
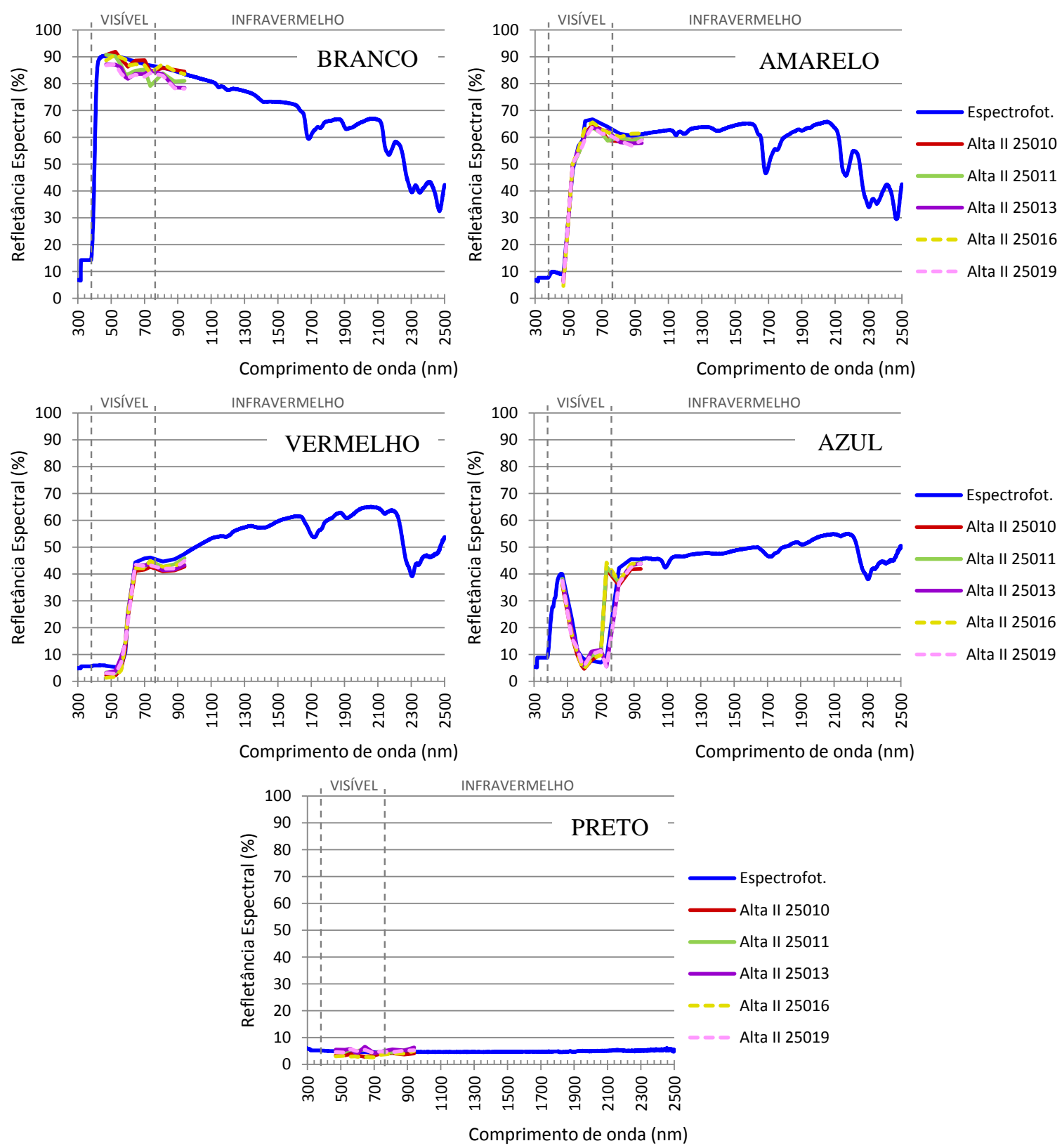


\section{Análise da influência da luminosidade do ambiente}

A segunda etapa de experimentos consistiu em medições das amostras sob diferentes condições de iluminação. A Figura 9 mostra as refletâncias espectrais médias de cada amostra, nas três condições analisadas, e também os valores de refletância de referência obtidos em laboratório com o espectrofotômetro.

Verifica-se que nas três condições foi possível obter curvas espectrais similares à curva do espectrofotômetro. Apenas na amostra amarela ocorreu um ponto com diferença significativa: no comprimento de onda de $940 \mathrm{~nm}$, a medição realizada sob o sol, sem proteção, resultou em valor muito superior aos demais.

Também é possível verificar que as amostras mais claras (branca e amarela) foram as que obtiveram resultados com maior influência da luminosidade. $\mathrm{Na}$ amostra amarela, a maior diferença entre refletância espectral obtida em medição com o espectrômetro Alta II e com o espectrofotômetro ocorreu na análise sob o sol sem proteção e foi de $17,5 \%$ no comprimento de onda $940 \mathrm{~nm}$, seguido de $7,8 \%$ no comprimento de onda $645 \mathrm{~nm}$. Na amostra branca, a maior diferença foi de $8,8 \%$ no comprimento de onda $560 \mathrm{~nm}$.

Mesmo com resultados muito semelhantes nas três condições, as medições noturnas foram as que apresentaram refletâncias mais próximas aos valores de referência em todas as amostras, com exceção da amostra preta. As medições realizadas sob o sol sem proteção foram as que apresentaram resultados mais distanciados da referência. A Figura 10 mostra um comparativo dos valores de refletância solar total para cada amostra avaliada.

Figura 9 - Refletâncias espectrais das cinco amostras, na faixa de 470 nm a 940 nm, medidas em diferentes condições de luminosidade
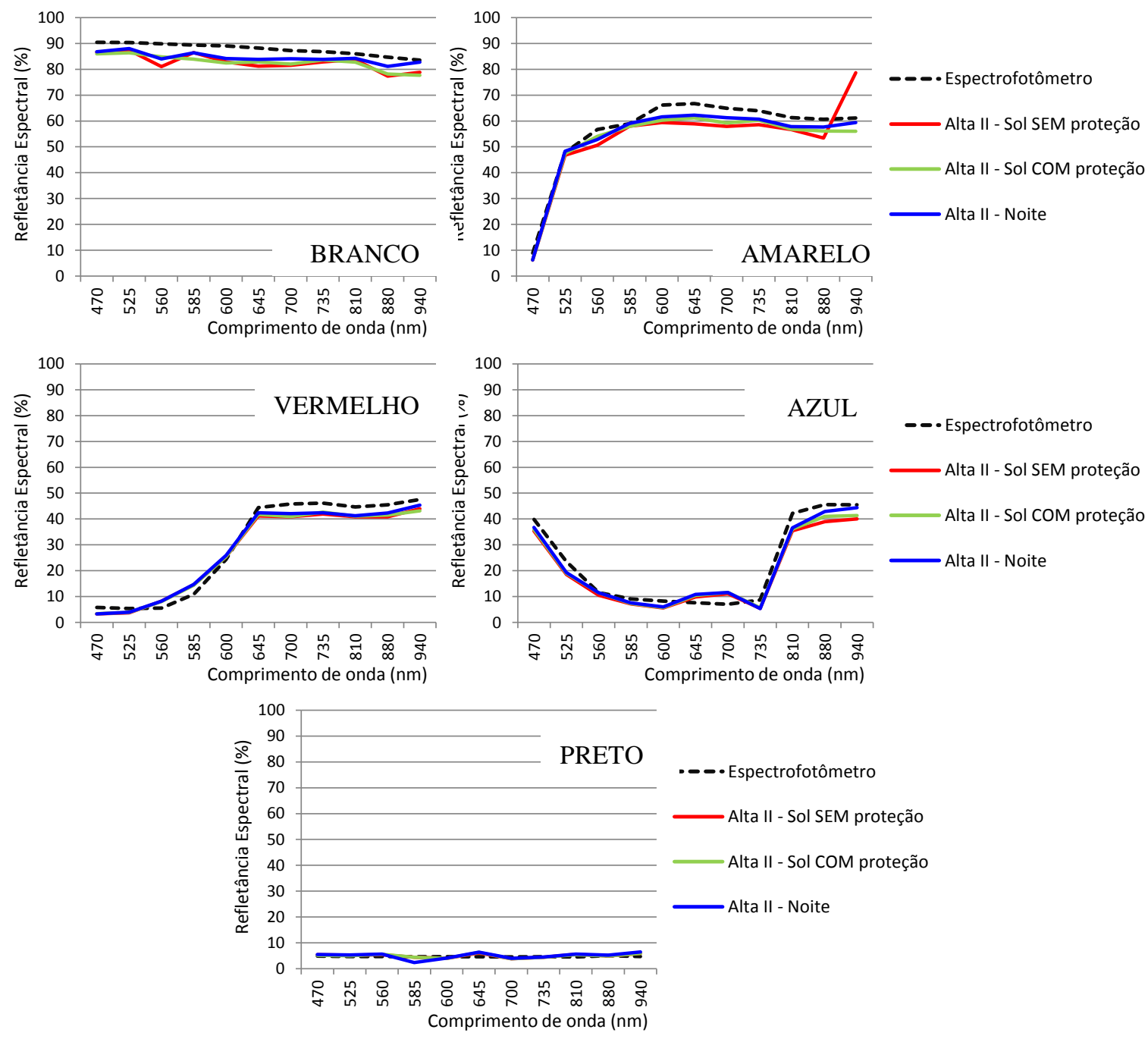
Figura 10 - Comparação dos resultados de refletância solar em diferentes condições de luminosidade (integrada na faixa de comprimentos de onda entre $470 \mathrm{~nm}$ e $940 \mathrm{~nm}$ )

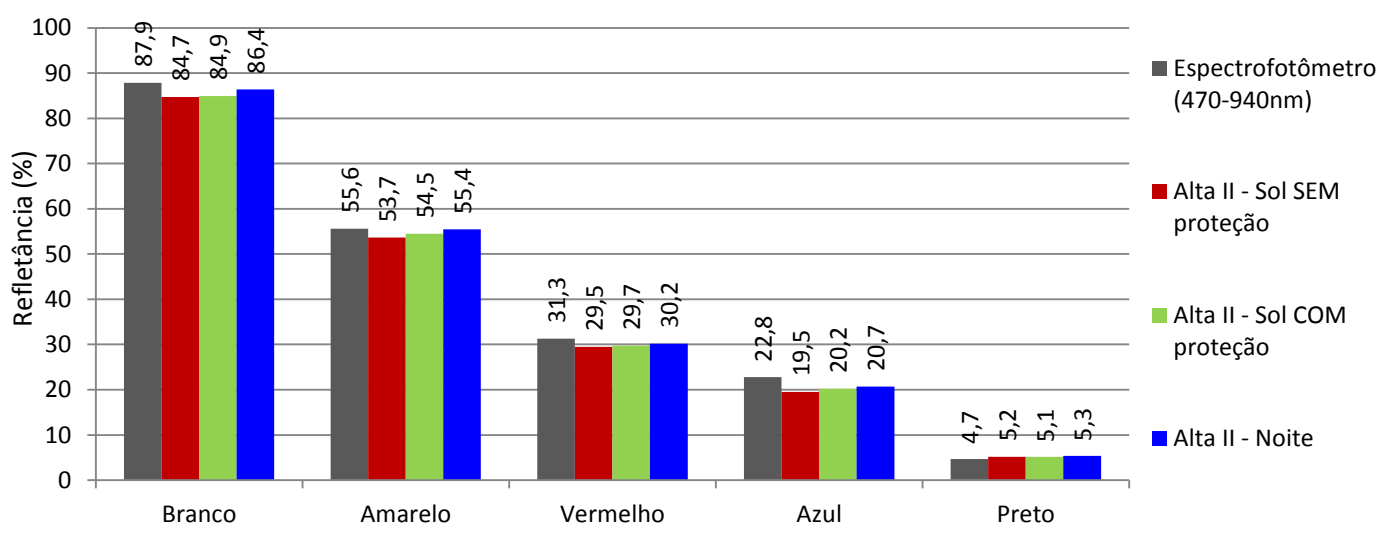

A maior diferença entre valores de refletância solar obtidos com o espectrômetro Alta II para a mesma amostra foi de $1,75 \%$ na amostra amarela $(55,43 \%$ à noite e 53,68\% sob o sol sem proteção). As menores diferenças ocorreram nos valores para a amostra preta (diferenças inferiores a 0,20\%).

Essa análise demonstrou que de fato existe influência da luminosidade do ambiente nos resultados de medições realizadas com o espectrômetro Alta II. Para amostras planas e lisas, como as analisadas aqui, e medições realizadas cuidadosamente, procurando evitar frestas entre amostra e equipamento, a luminosidade tem baixa influência nos valores de refletância. Porém, essa influência resulta em erros que, mesmo pequenos, devem ser evitados. Sendo assim, recomenda-se que as medições com o espectrômetro Alta II sejam realizadas prioritariamente em ambiente sem insolação direta. Quando isso não for possível, deve-se utilizar algum tipo de proteção nas bordas do equipamento em contato com a superfície, minimizando a incidência da luz.

\section{Análise da influência da rugosidade da superfície}

Os últimos experimentos realizados foram medições em duas paredes com pintura texturizada, sob diferentes condições de iluminação. Entretanto, nesta etapa, não foi possível realizar todas as medições propostas. As medições noturnas e também as medições diurnas com proteção foram realizadas sem problemas. No entanto, no caso das medições diurnas sem proteção, não foi possível completar o experimento com as cinco medições em cada superfície. Como as paredes analisadas nesta etapa eram texturizadas (Figura 4), a rugosidade não permitia o contato total entre a sua superfície da parede e a superfície posterior do espectrômetro. Isso significa que havia frestas permitindo a interferência da luz do ambiente no sensor localizado na base do espectrômetro. No período noturno, com pouca luminosidade, a infiltração de luz não foi suficiente para impedir as medições, apesar de ter possivelmente diminuído a precisão dos resultados. No período diurno com proteção, a influência da luz externa foi minimizada pela proteção utilizada (tecido escuro). Nas medições diurnas sem proteção, a elevada infiltração de luz pela base do equipamento inviabilizou parcialmente as leituras.

Nessas medições sob o sol sem proteção, quando o procedimento de medição era iniciado, o valor mostrado na tela do espectrômetro ficava oscilando constantemente, sem estabilizar, de forma que não era possível fazer a leitura. Após alguns instantes de oscilação, o equipamento desligava automaticamente. A leitura só foi possível em alguns períodos quando houve nebulosidade, com a diminuição da insolação sobre o equipamento. Sendo assim, na condição diurna sem nenhuma proteção, foram registrados os dados apenas de uma medição em cada amostra (e não cinco medições), que ocorreu em momento de céu parcialmente nublado.

Na Figura 11 são apresentados os resultados do experimento. Para as condições noturna e diurna com proteção, são mostrados valores de refletância espectral média (média das cinco medições em cada comprimento de onda). Para a condição diurna sem proteção, são mostrados os valores de refletância espectral da única medição registrada. 
Figura 11 - Refletâncias espectrais das duas superfícies texturizadas, medidas no Alta II, na faixa de $470 \mathrm{~nm}$ a $940 \mathrm{~nm}$

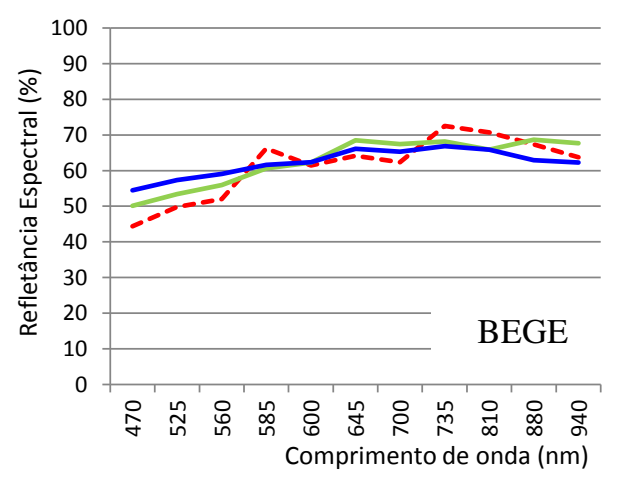

Percebe-se que, nas medições para as três condições, os resultados das superfícies rugosas apresentaram discrepâncias bem maiores que o ocorrido nas amostras planas. Nas duas superfícies, as curvas de refletância espectral da medição diurna com proteção e da medição noturna são mais próximas entre si, e a curva da medição diurna sem proteção é diferenciada.

A maior variação nos valores de refletância espectral da superfície bege foi de $10,1 \%$ no comprimento de onda $470 \mathrm{~nm}(54,5 \%$ à noite e $44,4 \%$ durante o dia sem proteção). A maior diferença na refletância espectral da superfície salmão foi de $16,2 \%$ no comprimento de onda 700 nm $(56,0 \%$ à noite e $39,8 \%$ durante o dia sem proteção).

Apesar das maiores discrepâncias terem ocorrido com relação à medição diurna sem proteção, mesmo entre as outras duas condições houve disparidades consideráveis. Na superfície bege ocorreu diferença máxima de $5,7 \%$ nas refletâncias espectrais do comprimento de onda $880 \mathrm{~nm}(62,9 \%$ à noite e $68,6 \%$ durante o dia com proteção). Na superfície salmão ocorreu diferença de $6,3 \%$ no comprimento de onda $525 \mathrm{~nm}(45,6 \%$ à noite e $39,3 \%$ durante o dia com proteção).

A Figura 12 mostra os valores de refletância solar calculados para as duas superfícies, nas três condições de exposição (integrados na faixa de comprimentos de onda do espectrômetro Alta II). $\mathrm{Na}$ amostra bege as variações foram menores e a diferença máxima foi de $1,1 \%$, entre as medições diurnas com e sem proteção. $\mathrm{Na}$ amostra salmão as diferenças foram relevantes, alcançando um máximo de $10,6 \%$ entre as medições noturna e diurna sem proteção.

Os resultados observados para as duas amostras (bege e salmão) não permitem concluir se o espectrômetro Alta II pode ser usado em superfícies rugosas gerando resultados confiáveis. Uma quantidade maior de avaliações ainda é necessária para uma recomendação definitiva da aplicação ou não do equipamento nesse tipo de superfície. Por isso, o uso do espectrômetro Alta II deve ser visto com muita cautela em superfícies rugosas, independentemente da condição de iluminação do ambiente. Para superfícies com rugosidade elevada, a melhor opção normalizada recomendada como base comparativa é o teste pela E1918 (AMERICAN..., 2006).

\section{Análise do uso do Alta II na normatização brasileira}

Os regulamentos brasileiros de eficiência energética em edificações, em vigência atualmente, procuraram inserir a absortância solar em seus critérios de análise. O texto dos regulamentos recomenda a utilização dos métodos de medição reconhecidos pelas normas E1918 (AMERICAN..., 2006), E903 (AMERICAN..., 2012a) e Standard 74 (AMERICAN..., 1988). Entretanto, com a dificuldade de aquisição e manutenção (alto custo) dos equipamentos indicados nessas normas, poucos projetistas, fornecedores ou fabricantes têm realizado tais medições em seus produtos. Em geral, adotam-se valores da NBR 15220-2 (ABNT, 2005) ou são realizadas medições não normatizadas adotando o procedimento de verificação com o Alta II. Tendo em vista a incerteza de aproximadamente $\pm 0,10 \quad$ (absoluto, considerando a refletância/absortância variando de 0 a 1) nos resultados obtidos com o espectrômetro Alta II, são feitas a seguir algumas ponderações sobre a aplicabilidade desse método alternativo com respeito às necessidades dos regulamentos brasileiros. 
Figura 12 - Comparação dos resultados de refletância solar em diferentes condições de luminosidade (integrada na faixa de comprimentos de onda entre $470 \mathrm{~nm}$ e $940 \mathrm{~nm}$ )

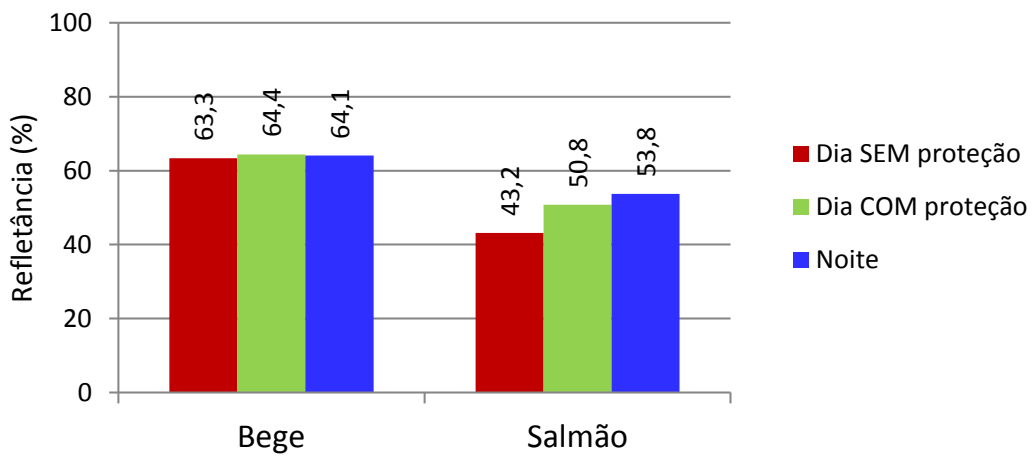

No RTQ-C (INSTITUTO..., 2010), a absortância solar $(\alpha)$ está inserida como um dos pré-requisitos. Para obtenção da etiqueta de nível A, existe o prérequisito de utilização de materiais de revestimento externo de paredes e coberturas com absortância solar menor que 0,50 , válido para as zonas bioclimáticas 2 a 8 . Sendo assim, no caso do RTQ$\mathrm{C}$, considera-se que atendem ao pré-requisito para nível A os materiais cujos valores de absortância solar, determinados a partir de medições com o espectrômetro Alta II, estiverem na seguinte condição: $\alpha<0,40$. Materiais que apresentarem valores de absortância solar, determinados com o espectrômetro Alta II, maior ou igual a 0,40 , deverão obrigatoriamente ser reavaliados por meio de um dos métodos normatizados.

No caso do RTQ-R (INSTITUTO..., 2012), a absortância solar $(\alpha)$ é uma das variáveis no cálculo do equivalente numérico da envoltória. Também há um pré-requisito relacionado à absortância que limita o valor da transmitância térmica do envoltório, baseado na NBR 15575 (ABNT, 2013). Tendo em vista a relevância dessa variável para o RTQ-R, nesse regulamento considera-se que podem ser aceitos como resultado final os valores da absortância solar obtidos com o equipamento Alta II acrescidos de $0,10\left(\alpha=\alpha_{\text {Alta II }}+0,10\right)$.

Na NBR 15575 (ABNT, 2013), a absortância solar é utilizada como limitadora para o critério de transmitância térmica de coberturas e paredes externas. No caso das paredes externas, a absortância solar acima ou abaixo de 0,6 indica diferentes valores máximos admissíveis para a transmitância térmica. Nas coberturas, os diferentes valores máximos admissíveis para a transmitância térmica têm como critério a absortância solar acima ou abaixo de 0,6 para as zonas bioclimáticas 3 a 6 , e acima ou abaixo de 0,4 para as zonas bioclimáticas 7 e 8. Sendo assim, para aplicação da NBR 15575 (AMERICAN..., 2013), recomenda-se que podem ser aceitos os valores de absortância solar obtidos a partir de medições com o equipamento Alta II, com as seguintes exceções:

(a) para o critério de absortância solar de 0,6: valores determinados com o Alta II no intervalo $0,5 \leq \alpha \leq 0,7$ devem obrigatoriamente ser reavaliados através de um dos métodos normatizados; e

(b) para o critério de absortância solar de 0,4: valores determinados com o Alta II no intervalo $0,3 \leq \alpha \leq 0,5$ devem obrigatoriamente ser reavaliados através de um dos métodos normatizados.

É importante salientar que as recomendações de uso do espectrômetro Alta II conforme os critérios apresentados neste item são restritos ao cálculo da refletância solar a partir do método indicado neste trabalho, para superfícies lisas e planas. Não são consideradas aqui possíveis correlações existentes entre dados medidos com o equipamento Alta II e medições com espectrofotômetros para a mesma amostra.

\section{Conclusões}

Os experimentos deste estudo demonstraram que os valores obtidos a partir de medições com o Alta II não representam com precisão a refletância solar das superfícies medidas, pois o equipamento não é capaz de fornecer dados da parcela infravermelha do espectro solar. Os resultados apenas demostram de forma satisfatória a refletância na parcela visível do espectro e de alguns comprimentos do infravermelho. Sendo assim, esses valores devem ser utilizados apenas como um indicativo da real refletância solar da superfície.

As análises realizadas neste estudo, considerando o espectro solar (300-2500 $\mathrm{nm})$, mostraram que a partir da incerteza máxima encontrada na avaliação de repetibilidade $(0,82 \%)$ e na comparação com o valor de referência do espectrofotômetro $(10,12 \%)$, o erro máximo estimado pela soma quadrática das 
incertezas é de $\pm 10,15 \%$, ou, em termos absolutos, aproximadamente $\pm 0,10$.

É importante destacar que as amostras utilizadas nessa avaliação foram obtidas com a aplicação de tintas convencionais, logo a incerteza apresentada neste artigo não é válida para medições em superfícies com aplicações de materiais "frios" (cool paints ou cool surfaces). Para esses materiais, a incerteza tende a ser maior.

Conclui-se, ainda, que a luminosidade do ambiente pode influenciar os resultados de medições realizadas com o Alta II, sendo essencial evitar frestas entre a amostra e a base do espectrômetro e priorizar ambientes sem insolação direta sobre a amostra. Quando isso não for possível, deve-se utilizar algum tipo de proteção sobre o equipamento, minimizando a incidência da luz. Por fim, pode-se afirmar que o Alta II tem condições de ser utilizado para análises de superfícies planas e lisas. Para medições de superfícies rugosas, os resultados não foram conclusivos, sendo prudente adotar nesses casos um método normatizado adequado (ver indicações em Pereira et al. (2015)).

\section{Referências}

\begin{abstract}
AMERICAN SOCIETY FOR TESTING AND MATERIALS. C1549: standard test method for determination of solar reflectance near ambient temperature using a portable solar reflectometer. West Conshohocken, 2009.
\end{abstract}

\section{AMERICAN SOCIETY FOR TESTING AND} MATERIALS. E1918: standard test method for measuring solar reflectance of horizontal and lowsloped surfaces in the field. West Conshohocken, 2006.

\section{AMERICAN SOCIETY FOR TESTING AND MATERIALS. E903: standard test method for} solar absorptance, reflectance and transmittance of materials using integrating spheres. West Conshohocken, 2012a.

AMERICAN SOCIETY FOR TESTING AND MATERIALS. G173 - 03 (Reapproved 2012): standard tables for reference solar spectral irradiances: direct normal and hemispherical on $37^{\circ}$ tilted surface. West Conshohocken, 2012b.

\section{AMERICAN SOCIETY OF HEATING, REFRIGERATING AND AIR-CONDITIONING ENGINEERS. ASHRAE Handbook:}

Fundamentals. Atlanta, 2005.

\section{AMERICAN SOCIETY OF HEATING,} REFRIGERATING AND AIR-CONDITIONING ENGINEER. Standard 74: method of measuring solar-optical properties of materials. Atlanta, 1988.
ASSOCIAÇÃO BRASILEIRA DE NORMAS TÉCNICAS. NBR 15220-2: desempenho térmico de edificações: parte 2: métodos de cálculo da transmitância térmica, da capacidade térmica, do atraso térmico e do fator solar de elementos e componentes de edificações. Rio de Janeiro, 2005.

\section{ASSOCIAÇÃO BRASILEIRA DE NORMAS} TÉCNICAS. NBR 15575: edificações habitacionais: desempenho. Rio de Janeiro, 2013.

CASTRO, A. P. A. S. et al. Medidas de Refletância de Cores de Tintas Através de Análise Espectral. Ambiente Construído, Porto Alegre, v. 3, n. 2, p. 69-73, abr./jun. 2003.

\section{DORNELLES, K. A. Absortância Solar de}

Superfícies Opacas: métodos de determinação e base de dados para tintas látex acrílica e PVA.

Tese (Doutorado em Engenharia Civil) - Programa de Pós-Graduação em Engenharia Civil, Universidade Estadual de Campinas. Campinas, 2008.

DORNELLES, K. A.; RORIZ, M. Métodos Alternativos Para Identificar a Absortância Solar de Superfícies Opacas. Ambiente Construído, v. 7, n. 3, p. 109-127, jul./set. 2007.

\section{INCROPERA, F. P. et al. Fundamentos de}

Transferência de Calor e de Massa. 6. ed. Rio de Janeiro: LTC, 2011.

\section{INSTITUTO NACIONAL DE METROLOGIA, NORMALIZAÇÃO E QUALIDADE} INDUSTRIAL. Portaria $\mathbf{n}^{\circ}$ 372, de 17 de setembro de 2010, com alterações. Regulamento Técnico da Qualidade para o Nível de Eficiência Energética de Edificações Comerciais, de Serviços e Públicas. Rio de Janeiro, 2010. Disponível em: <http://www.pbeedifica.com.br/etiquetagem/comer cial>. Acesso em: 30 abr. 2015.

INSTITUTO NACIONAL DE METROLOGIA, NORMALIZAÇÃO E QUALIDADE INDUSTRIAL. Portaria $\mathbf{n}^{\circ} \mathbf{1 8}$, de 16 de janeiro de 2012. Regulamento Técnico da Qualidade para o Nível de Eficiência Energética de Edificações Residenciais. Rio de Janeiro, 2012. Disponível em: <http://www.pbeedifica.com.br/etiquetagem/reside ncial>. Acesso em: 30 abr. 2015.

\section{LUNAR AND PLANETARY INSTITUTE.}

ALTA Reflectance Spectrometer. 2011.

Disponível em:

<http://www.lpi.usra.edu/education/products/spect rometer>. Acesso em: 30 abr. 2015. 
MARINOSKI, D. L. et al. Análise Comparativa de Valores de Refletância Solar de Superfícies Opacas Utilizando Diferentes Equipamentos de Medição em Laboratório. In: ENCONTRO NACIONAL DE CONFORTO NO AMBIENTE CONSTRUÍDO, 12., Brasília, 2013. Anais... Brasília, 2013.

MUNIZ, L. P.; PEZZUTO, C. C. Medições de Refletância Através do Espectrômetro Portátil ALTA II. In: ENCONTRO DE INICIAÇÃO CIENTÍFICA, 19., Campinas, 2014. Anais... Campinas: PUC, 2014.

PEREIRA, C. D. et al. Guia de Medição e Cálculo Para Refletância e Absortância Solar em Superfícies Opacas. Relatório de Pesquisa, CB3E - Centro Brasileiro de Eficiência Energética em Edificações, 2015. Disponível em: $<$ http://www.cb3e.ufsc.br/sites/default/files/Guia_ medicao_refletancia_CB3E_v1.pdf $<$. Acesso em: 30 out. 2015.
PEREIRA, C. D. Influência da Refletância e da Emitância de Superfícies Externas no Desempenho Térmico de Edificações. Florianópolis, 2014. Tese (Doutorado em Engenharia Civil) - Programa de Pós-Graduação em Engenharia Civil, Universidade Federal de Santa Catarina, Florianópolis, 2014.

SANGOI, J. M.; RAMOS, G.; LAMBERTS, R. Análise das Medições de Absortância Através do Espectrômetro ALTA II. In: ENCONTRO NACIONAL DE TECNOLOGIA DO AMBIENTE CONSTRUÍDO, 13., Canela, 2010. Anais... Canela: ANTAC, 2010.

SANTOS, E. I.; MARINOSKI, D. L.; LAMBERTS, R. Influência do Ambiente de Medição Sobre a Verificação da Absortância de Superfícies Opacas Utilizando um Espectrômetro Portátil. In: ENCONTRO NACIONAL DE CONFORTO NO AMBIENTE CONSTRUÍDO, 10., Natal, 2009. Anais... Natal: ANTAC, 2009.

\section{Agradecimentos}

Os autores agradecem ao CNPq, Capes, MCTI e Eletrobras pelos recursos financeiros aplicados na pesquisa.

\section{Cláudia Donald Pereira}

Departamento de Construção Civil, Centro de Tecnologia e Urbanismo | Universidade Estadual de Londrina | Rodovia Celso Garcia Cid Km 380 | Londrina - PR - Brasil | CEP 86055-900 | Tel.: (43) 3371-4649 | E-mail: cdp.donald@gmail.com

\section{Deivis Luis Marinoski}

Departamento de Expressão Gráfica | Universidade Federal de Santa Catarina | Centro de Comunicação e Expressão | Campus Universitário, Trindade | Florianópolis - SC - Brasil | Caixa Postal 476 | CEP 88040-970 | Tel.: (48) 3721-6613 |

E-mail: deivis.marinoski@ufsc.br

\section{Roberto Lamberts}

Departamento de Engenharia Civil, Centro Tecnológico | Universidade Federal de Santa Catarina | Tel.: (48) 3721-2390 | E-mail: roberto.lamberts@ufsc.br

\section{Saulo Güths}

Departamento de Engenharia Mecânica, Centro Tecnológico | Universidade Federal de Santa Catarina | Tel.: (48) 3721-7709 |

E-mail: saulo@Impt.ufsc.br

\section{Enedir Ghisi}

Departamento de Engenharia Civil, Centro Tecnológico | Universidade Federal de Santa Catarina | Tel.: (48) 3721-2115 | E-mail: enedir.ghisi@ufsc.br

\section{Revista Ambiente Construído}

Associação Nacional de Tecnologia do Ambiente Construído

Av. Osvaldo Aranha, $99-3^{\circ}$ andar, Centro

Porto Alegre - RS - Brasil

CEP 90035-190

Telefone: +55 (51) 3308-4084

Fax: +55 (51) 3308-4054

www.seer.ufrgs.br/ambienteconstruido

E-mail: ambienteconstruido@ufrgs.br 